\title{
The Opera Diva, the Catalyst, and the Big Smash
}

\author{
Ragnar Larsson* \\ Department of Chemical Engineering, Lund University, Sweden
}

Submission: October 03, 2020; Published: October 27, 2020

"Corresponding author: Ragnar Larsson, Department of Chemical Engineering, Lund University, Lund, Sweden

Keywords: Magnetite; Molecular hydrogen; Nitrogen; Catalyst; Iron compounds; Metal atom; Carbonyl sulfide; Volcanic eruptions; Energy; Amino acid; Glycine; Hydrogen atom; Inorganic molecules; Electric discharges

\section{Mini Review}

Some of you might have heard or read about the tale of the opera singer who could really sing in tune and did so extremely well. Once she decided to try to approach the tone quality of the clink of a glass object on her table when that object was gently struck. It seemed that she succeeded, and her voice turned stronger and stronger and ----- smash! --- suddenly the glass object was split to pieces. The two vibration systems (the singer and the glass structure) were in harmony, as a musician would say, they were in resonance, a physicist would say.

It struck me, a few decades ago [1,2] when realizing that in many cases of catalytic reactions the activation energy was changing stepwise for a slight change of reaction conditions (such as different carriers), that this tale could be an illustration of how catalysis works: The catalyst corresponds to the opera diva, full of energy and wanting to share with others. The glass object corresponds to the molecule that reacts with bonds breaking, following energy transfer from the catalyst. Therefore, we have called this model of catalysis SET (Selective Energy Transfer). In the following we will indicate a few examples of such resonance effects.

A. One of the best known of technical catalysts is the one that was developed by Fritz Haber and coworkers. Just before 1914 Alwin Mittasch, after intensive experimentation, stated that an iron oxide compound (like magnetite, $\mathrm{Fe}_{3} \mathrm{O}_{4}$ ) was a very efficient catalyst for the reaction of nitrogen with molecular hydrogen. It is reasonable to assume that the critical vibration of the reactant is a $\mathrm{M}-\mathrm{N}=\mathrm{N}$ bending (Figure 1 ). Analysis of the activation energies of a series of iron compounds, favouring the reaction with $\mathrm{H} 2$, indicated that the critical vibration was $368 \pm 8 \mathrm{~cm}^{-1}$. Further, a strong bending vibration of magnetite is found to be at $364 \mathrm{~cm}^{-1}$ (Figure 2). Thus, one can conclude that energy is donated from the magnetite catalyst to the $\mathrm{N}_{2}$ molecule, in contact with a metal atom. The adsorbing orbital is a $\mathrm{M}-\mathrm{N}=\mathrm{N}$ as indicated above $[3,4]$. This finding agrees with the SET model. For further details, vide the reference [5].

B. Let us now indicate the results of some recent work [6] on prebiotic reactions. In prebiotic times one frequently appearing catalyst was COS (carbonyl sulfide), streaming out of volcanic eruptions. This compound is characterized by a very strongly absorbing vibration at $2079 \mathrm{~cm}^{-1}$. Consequently, an activated COS molecule could easily emit energy at the same frequency, $2079 \mathrm{~cm}^{-}$ ${ }^{1}$. Following SET, it could serve as a catalyst if the reacting, energy accepting molecule contained a vibration with about the same frequency. It could also be so that one quantum of this energy $\left(2079 \mathrm{~cm}^{-1}\right)$ acted in resonance with two quanta of the reactant of about $1040 \mathrm{~cm}^{-1}$. This is exemplified here by the "condensation" of two amino acids to form a peptide bond:

$$
\begin{gathered}
\mathrm{H}_{2} \mathrm{~N}-\mathrm{CHR}^{\prime}-\mathrm{COOH}+\mathrm{H}_{2} \mathrm{~N}-\mathrm{CHR}{ }^{\prime \prime}-\mathrm{COOH}=>\mathrm{H}_{2} \mathrm{~N}-\mathrm{CHR}^{\prime \prime}-\mathrm{CO}-\mathrm{NH}- \\
\mathrm{CHR}-\mathrm{COOH} .+\mathrm{H}_{2} \mathrm{O}
\end{gathered}
$$

\section{The question is now, how can this happen?}

To answer this question, we must scrutinize the IR spectrum of an amino acid, e.g. glycine as metal complex. One finds that for, e.g., Ni(glycinate)2 there is a vibration at $1038 \mathrm{~cm}^{-1}$ [7]. This agrees with the requirement, stated above. But, even more, this vibration is a so-called wagging vibration of the $\mathrm{NH}_{2}$ group, where the $\mathrm{H}$ atoms are moving perpendicularly against the $\mathrm{NH}_{2}$ plane [7]. 
When this vibration is sufficiently excited - by getting energy from the catalyst-the sp3 orbital pattern is changed into a sp2 one. This means that one hydrogen atom is set free and can interact with the $\mathrm{OH}$ group of the other amino acid, forming water, $\mathrm{H}_{2} \mathrm{O}$.

Consequently, an $\mathrm{NH}-\mathrm{C}=\mathrm{O}$ group is formed, binding the two molecules together. This is agreeing with the SET model. One can note that when Stanley Miller [8] in 1953 had shown that amino acids were formed when a mixture of simple inorganic molecules was bombarded by electric discharges (thunder storms), he and coworkers tried to achieve such a protein-creating condensation, but with no success. This shows the importance of using appropriate catalysts.

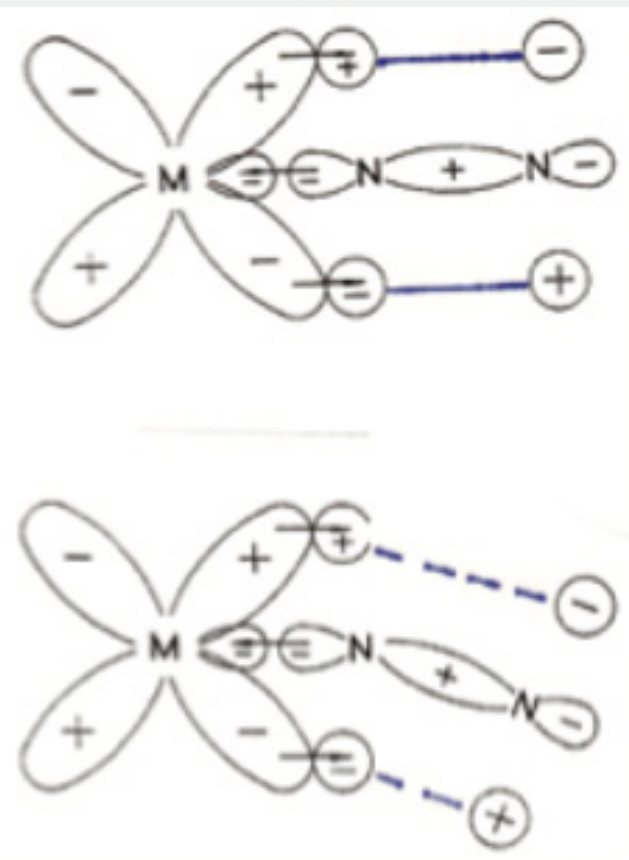

Figure 1: Upper picture: Schematic view of the M-N-N bonding following Chatt and Duncanson [3]. (The plus and minus signs refer to the sign of the wave function and not to the distribution of charge). Lower picture: Schematic description of the change of bonding and polarity of the bonds when the M-N-N unit is bending around the central $\mathrm{N}$ atom. When the outermost $2 \mathrm{p}$ orbital comes near already filled orbitals, charge repulsion makes the electrons to flow outwards. Hence, a polarity perpendicular to the M-N-N direction is established which facilitates the attack of an $\mathrm{H}$-atom, creating an $\mathrm{sp}-\mathrm{N}-\mathrm{H}$ bond.

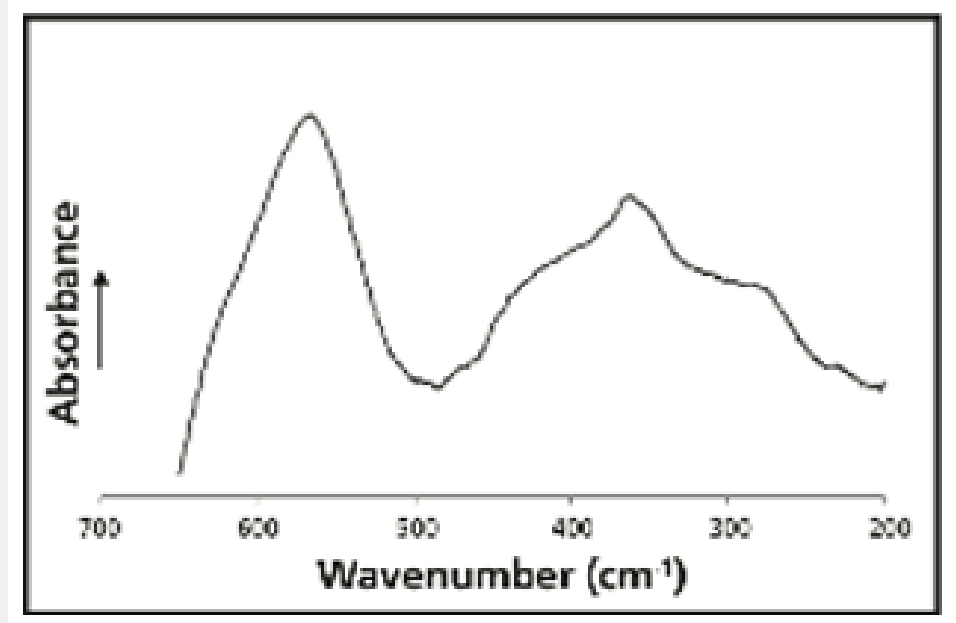

Figure 2: Far IR spectrum of a synthetic magnetite sample [4]. Stretching vibrations at left, bending ones to. the right. 


\section{References}

1. Larsson R (1987) On the Stepwise Change of the Energy of Activation of Catalytic Reactions. Z Physik Chemie Leipzig 268: 721-732.

2. Larsson R (1989) A Model of Selective Energy Transfer at the Active Site of the Catalyst. J Mol Catal 55: 70-83.

3. Chatt J (1989) Nitrogen Complexes of Platinum Metals: Pointers to a Mechanism of Fixation. Platinum Metals Rev 13: 9-14.

4. Roonasi P, Holmgren A (2009) Contribution to ref [5] Luleå Technological University.
5. Larsson R (2019) An analysis of ammonia synthesis by the model of Selective Energy Transfer (SET). Ann Math Phys 2(1): 038-050.

6. Larsson R, Malek A (2020) The Transformation by Catalysis of Prebiotic Systems to Useful Biochemicals; A Perspective Based ion IR Spectroscopy of the Primary Chemicals: I. The Syntheis of Peptides by the Condensation of Amino Acids Appl Sci 10(3): 928-940.

7. Nakamoto K (1986) Infrared and Rman Spectra of Inorganic and Coordination Compounds ( $4^{\text {th }}$ Edn) John Wiley \& Sons: New York, NY, USA, pp. 236.

8. Miller S L (1953) A Production of Amino Acids Under Possible Primitive Earth Conditions. Science 117: 528-529.

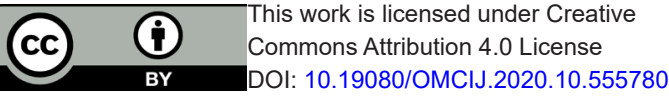

